\title{
Towards a Smart Campus for Qassim University: An Investigation of Indoor Navigation System
}

\author{
Mohammed Hadwan ${ }^{1,2,3, *}$, Rehan Uallah $\operatorname{Khan}^{1,2}$, Khalil Ibrahim Mohammad Abuzanouneh ${ }^{1,2}$ \\ ${ }^{1}$ Department of Information Technology, College of Computer, Qassim University, Buraydah, 51452, Saudi Arabia \\ ${ }^{2}$ Intelligent Analytics Group (IAG), College of Computer, Qassim University, Buraydah, 51452, Saudi Arabia \\ ${ }^{3}$ Deptartment of Computer Science, Faculty of Applied Sciences, Taiz University, Taiz, 6803, Yemen
}

\begin{tabular}{l} 
A R T I C L E I N F O \\
\hline Article history: \\
Received: 24 September, 2020 \\
Accepted: 21 November, 2020 \\
Online: 27 November, 2020 \\
\hline Keywords: \\
Indoor positioning \\
Smart cities \\
Bluetooth low energy (BLE) \\
Internet of Things (IoT)
\end{tabular}

\section{Introduction}

Over the last decade, a smart city is one of the emerging concepts that aims to provide a smart livable environment for the resident. Cities as Singapore, Barcelona, San Francisco, London, etc., is an example of cities that apply the concept of smart cities. In [1], the author defined a smart city as "A city well performing built on the 'smart' combination of endowments and activities of self-decisive, independent and aware citizens". The Internet of Things (IoT) paradigm allows cities to manage and control every aspect of the city from buildings, roads, railways, to airports and traffics in a smart manner. IBM smarter planet project adopted the term of the smart city [2]. The smart city relies on six key factors: smart governance, smart people, smart economy, smart

\footnotetext{
"Corresponding Author: Mohammed Hadwan, Email: m.hadwan@qu.edu.sa
}

\begin{abstract}
With the advancements in technology, smart entities are becoming increasingly intelligent, therefore, increasing their interaction capabilities with their surrounding environment. Apart from the traditional smart low profile devices, these entities now involve cars, obiles, televisions, and extend to universities and smart cities. One of the bi-product of the smart cities is the emergence of the concept of smart campus. The smart campus is a surrounding devices takes place using the paradigm of the Internet of Things (IoT). The Qassim University (QU) is considerably a large university having thousands of students and hundreds of functional units in the central building and also spread across the different cities of the Al-Qassim province. Therefore, the QU can be considered as a small city where many elements need to be connected and decisions be made. The QU thus represents an optimal and practical scenario for the concept of smart campus. With this spirit, the goal of this research is thus to investigate an Indoor Navigation System (INS) as a suitable platform for the QU. As such, the paper reviews the current technologies and opt for the best available and optimal options. For implementation and simulation, the BLE beacon is lected and user data is analyzed to design a mobile application that includes all the services requested by the users. The system architecture in addition to a 2D map presented in this research will help in identifying the locations of BLE beacons to cover the specific area. The work in this paper is conducted on the main campus of the QU; however, the extension to other setups involves minimum or similar infrastructure.
\end{abstract}

environment, smart life, and smart traffic [3]. Nowadays, the typical universities are considered as small cities that include most of the services available in the cities. The advancement of new technologies such as Artificial intelligence, IoT, and the availability of High-speed internet plays a big role in changing the living environment to be smart than ever before [3]. Smart universities also called smart campuses to compose one of the branches of the smart city concept that concern about every aspect inside the university; students, staff, visitors, classrooms, buildings, equipments, etc.[4]. Due to the popularity of the term of smart campus, we will use it in this research to refer to smart university. The smart campus concept can offer many benefits such as save cost and time, automate maintenance, protect the environment, automate students and staff attendance, track occupancy as well and many other benefits [5]. Several 
applications have been developed to make our campuses smart such as smart buildings, smart parking, smart learning, smart campus management, and maintenance, etc. [3].

Navigating inside large buildings, such as malls, hospitals, airports, and campuses, using an INS to help users to reach their preferred destination is highly required. INS is investigated in this research due to the huge size of QU main campus that has a similar interior design where finding places is a very difficult task for visitors and even for students and staff as well. The available infrastructures at the QU campus encourage us to explore this idea to make campus life easier and smarter. The main problem of INS is the signal unavailability of a Global Positioning System (GPS) inside buildings because of the walls and other barriers [6]. Smartphones, smart glasses, smart watches are widely spread and used heavily for INS because of the different sensors that is equipped with. Therefore, the aim of this paper is to investigate and identify the obstacles and barriers that could stand against devolving suitable INS for QU main campus.

\section{Background}

Smart cities with their different technologies and services are one of the active research areas where many survey papers have been published recently $[1-5,7,8]$. The Kingdom of Saudi Arabia is among the countries that apply this concept to change its traditional cities to become smart cities [9]. The smart campus is a concept where many universities working on several projects to adopt this concept such as King Fahd University of Petroleum and Minerals[10], Lancaster University [11], University of Malaga [12], University of New South Wales in Australia [13], etc. The services and applications offered by smart campus are varied. These services aim to make the universities surrounding smart includes but not limited to buildings, laboratories, libraries, classroom, attendance system, grid, learning, parking, navigation, waste and water management and etc. For more information about the smart campus, services refer to $[3,4,14-15]$. Due to the complex mixture of elements and devices to be connected, many expected and unexpected problems might appear and need to be addressed. For instance, internet coverage [16], energy consumption [17], sensory network [18], location-based services [19] etc.

In [20] researchers discussed different types of INS in the literature and highlighted the accuracy problem. In [21], the researchers give recommendations for the user interface design of INS based on the case study conducted by them. They found that it is important not to put heavy details in the map and to simplify the graphical layout. In [22] an android-based application is introduced for indoor navigation inside public buildings using Near Field Communication NFC and Quick Response codes QR. Several features include finding a destination with the shortest path, store the location of car parking, finding the nearest toilet, etc. Smart phones used for INS as in [23] where mobiles used for navigation using wireless access point fingerprints help an individual to get their direction with the indoor space using navigation application. Researchers in [24] Proposed Vision-based approaches for mobile indoor localization based on the combination of Virtual Reality (VR) and Augmented Reality (AR) in order to help in ensuring the accuracy of the localization.
Since the focus of this paper is to develop an Indoor Navigation platform for QU, in the following section we will review the current technologies used for INS. The researches in INS is still active, several survey papers published currently to explore it in detail as in [6, 25-27]. As the signal of GPS cannot reach the devices in indoor areas, several telecommunication technologies were introduced to overcome this problem. For example, Wireless Fidelity (Wi-Fi) [28, 29], Radio Frequency Identification (RFID) [30], Infrared technology (IR) [31], Ultra-Wide Band (UWB) signals [32] and Bluetooth low energy (BLE) beacons[33].

BLE beacons are a relatively new technology with the advantage of low energy consumptions that small batteries can be used for months up to years [34]. Based on the research conducted by [35] to study the localization accuracy between BLE and WIFI. The findings show that BLE was more accurate than WIFI at identical places. According to [36] BLE is a promising technology that has a low deployment cost and appropriate for most mobile devices. iBeacon is the name of Apple's brand of BLE technology based on the micro-localization and the interaction of a mobile device [34]. BLE beacons need to care about the radiation pattern of a given device and possible attenuation element in the chosen places [37].

\section{Data Collection and Analyses}

User preferences are very important to build effective systems. Therefore, a questionnaire developed and published to collect the user preferences and other necessary data to get insight into the difficulties they faced inside the QU campus. Responses collected from 454 students, lecturers, and general staff. The questions dedicated to familiar and unfamiliar users for the QU campus. The main services and tools requested by the respondent to be available in the QU INS application are presented in table 1.

Table1: The percentage of each place \& service required by users

\begin{tabular}{|l|l|c|}
\hline No. & Places \& Services & $\%$ \\
\hline 1 & $\begin{array}{l}\text { Places and services around current location (Prayer } \\
\text { room, toilet, cafeterias, garden, shops, Photostat, } \\
\text { parking, students clubs, gardens etc.) }\end{array}$ & $98 \%$ \\
\hline 2 & Timetable and office hours information of staff & $96 \%$ \\
\hline 3 & Search by name, Map and around current location & $95 \%$ \\
\hline 4 & Announcements & $93 \%$ \\
\hline 5 & Laboratories & $91 \%$ \\
\hline 6 & Location of new events & $91 \%$ \\
\hline 7 & Classrooms location & $90 \%$ \\
\hline 8 & Examination room location & $90 \%$ \\
\hline 9 & Staff members offices & $87 \%$ \\
\hline 10 & Emergency exits & $81 \%$ \\
\hline 11 & Library & $74 \%$ \\
\hline 12 & Administration offices & $31 \%$ \\
\hline
\end{tabular}

The gender, age, user type (student, lecturer, staff, or visitor), preferred services to be available in the system, and other questions been asked and responses obtained. The collected data have been analyzed and important information extracted as follows, refer to Figure 1 and Figure 2: 
1- $91 \%$ Preferred to have an application that can help to ease the indoor navigation inside the QU campus.

2- $73 \%$ of respondents are facing some difficulties in finding locations especially when they visit the QU main building.

3- $100 \%$ of respondents never used an INS before.

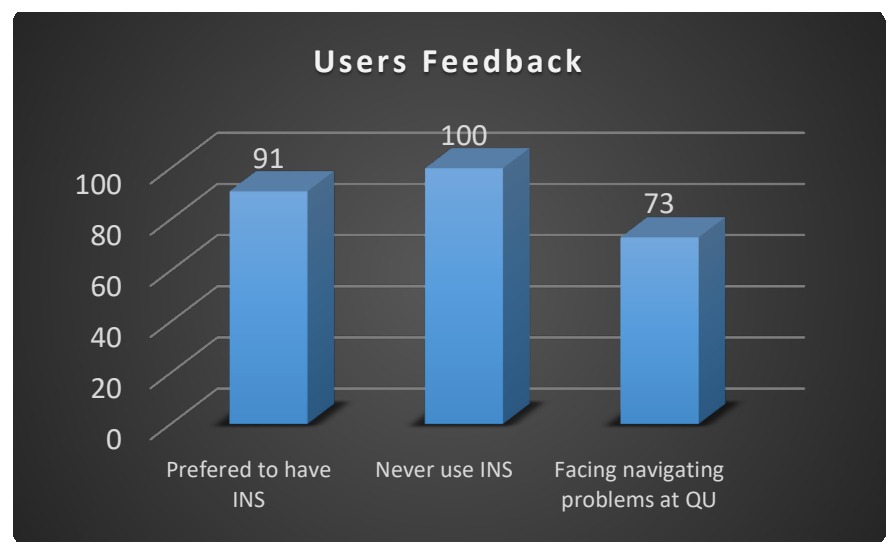

Figure 1: The user's responses to the general questions in the questionnaire.

\section{Proposed INS for QU}

Based on the extracted information from the questionnaire, a framework for the INS of QU is developed. Figure 3 shows the framework for QU INS, which includes two sections. A section for users where they can search for locations, navigating to desired locations, positioning their current locations, and access the main page where they can modify the settings based on their desire.
The second section is for the developers, where they can develop the INS software, upgrade hardware, add locations, and its information to the database and update the navigation map.

Figure 4 presents the system flowchart for the users where they can search for a location, positioning their selves, and navigate to the desired location. Searching can be through the map our using keyword. For positioning service where it shows the current location of the user in addition to the nearest services around. The navigation service used to guide the users from their location to a specific location inside the building. Based on the literature, BLE beacons are a new, cheap, and popular technology for INS. This encourages us to use BLE beacons to assist in navigation and positioning the users. BLE beacons broadcast their identifier to the nearby devices.

In order to deploy the minimum number of BLE beacon devices, Figure 5 shows the device's location that is enough to cover a single location at the Department of IT, where each beacon covers approximately 62 maters. Each BLE beacon has its own unique ID and for every wall, a boundary segmentation starts from 0 for the first wall, 1 for the second, and so on.

Walls need to determine the sides either left or right. To calculate the position of an object in indoor areas, at least three timestamps from different BLE beacons are needed. A mobile application is designed based on the gathered requirements from the users. Figure 6 shows some examples of screen shots for QU INS. The users can search by names, on a map, or around their current location.

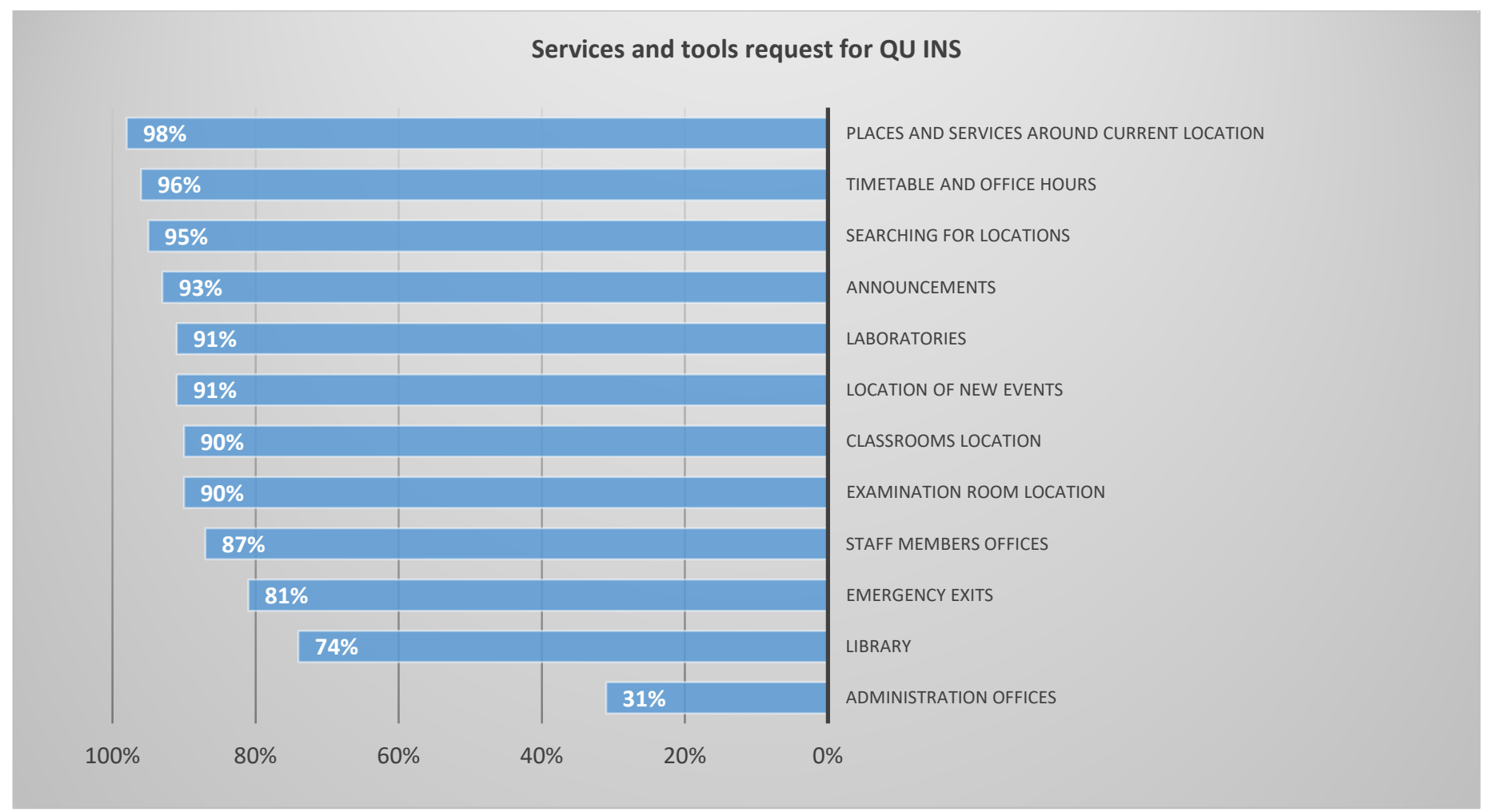

Figure 2: Users' desired services to be included in the INS at QU 


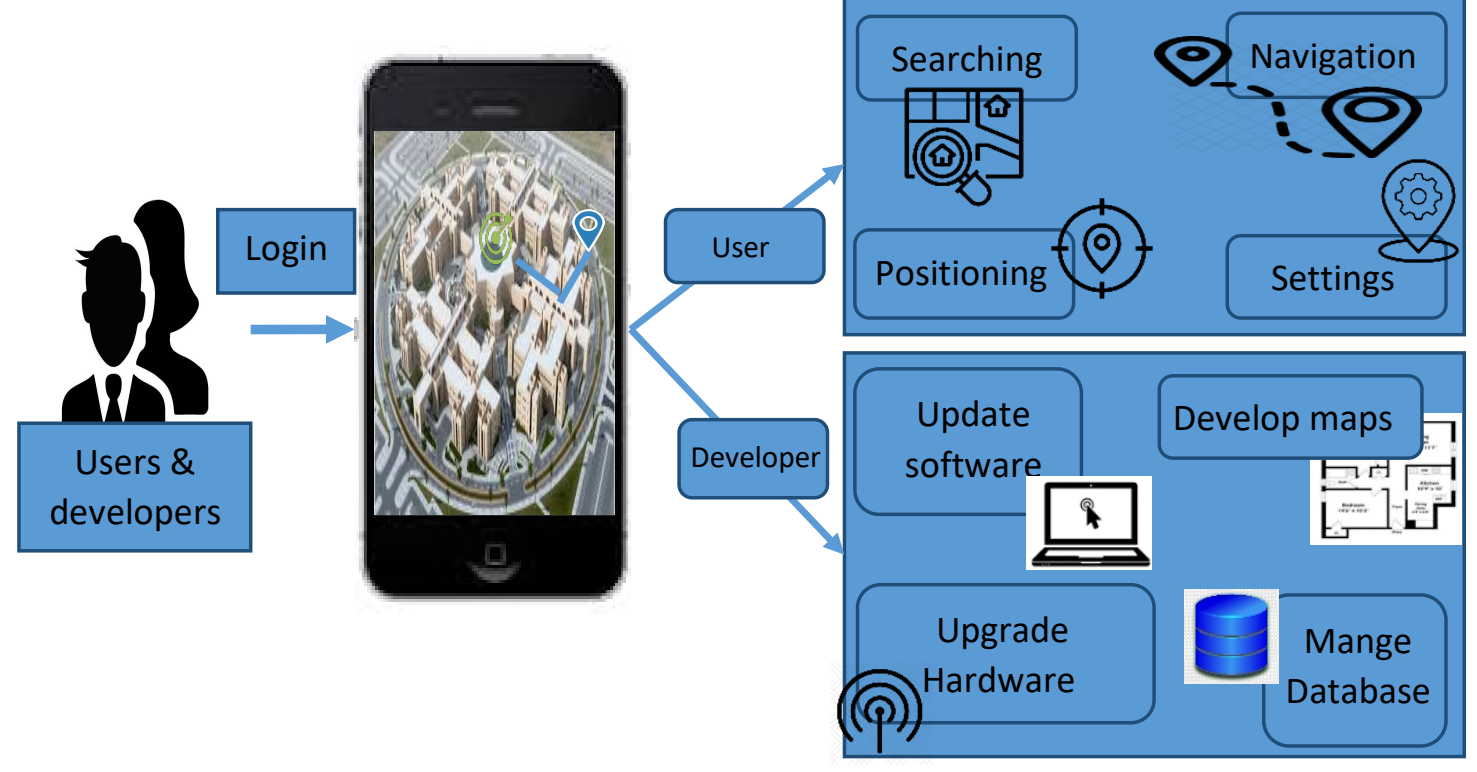

Figure 3: Framework for INS at QU

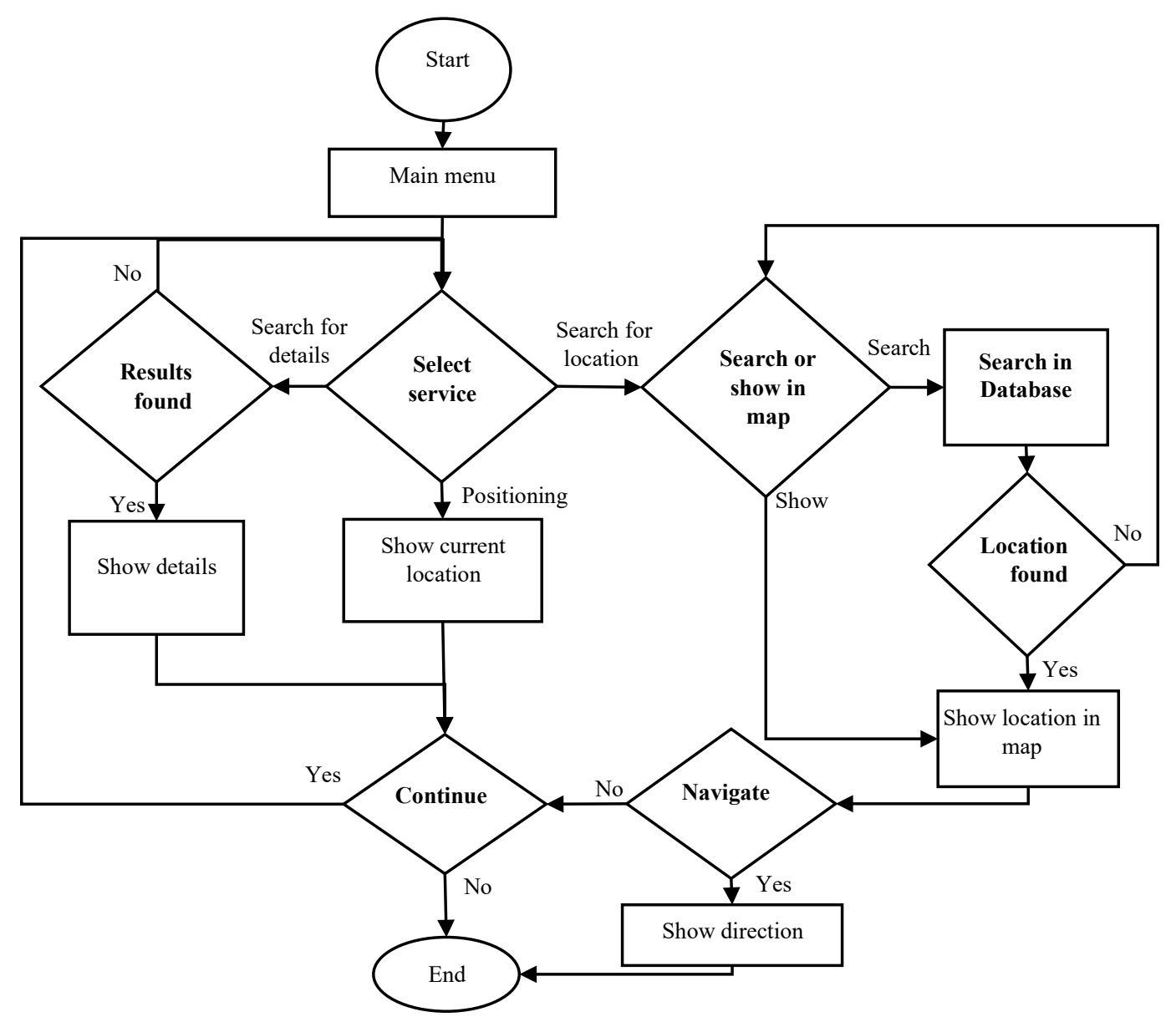

Figure 4: Users' flowchart. 


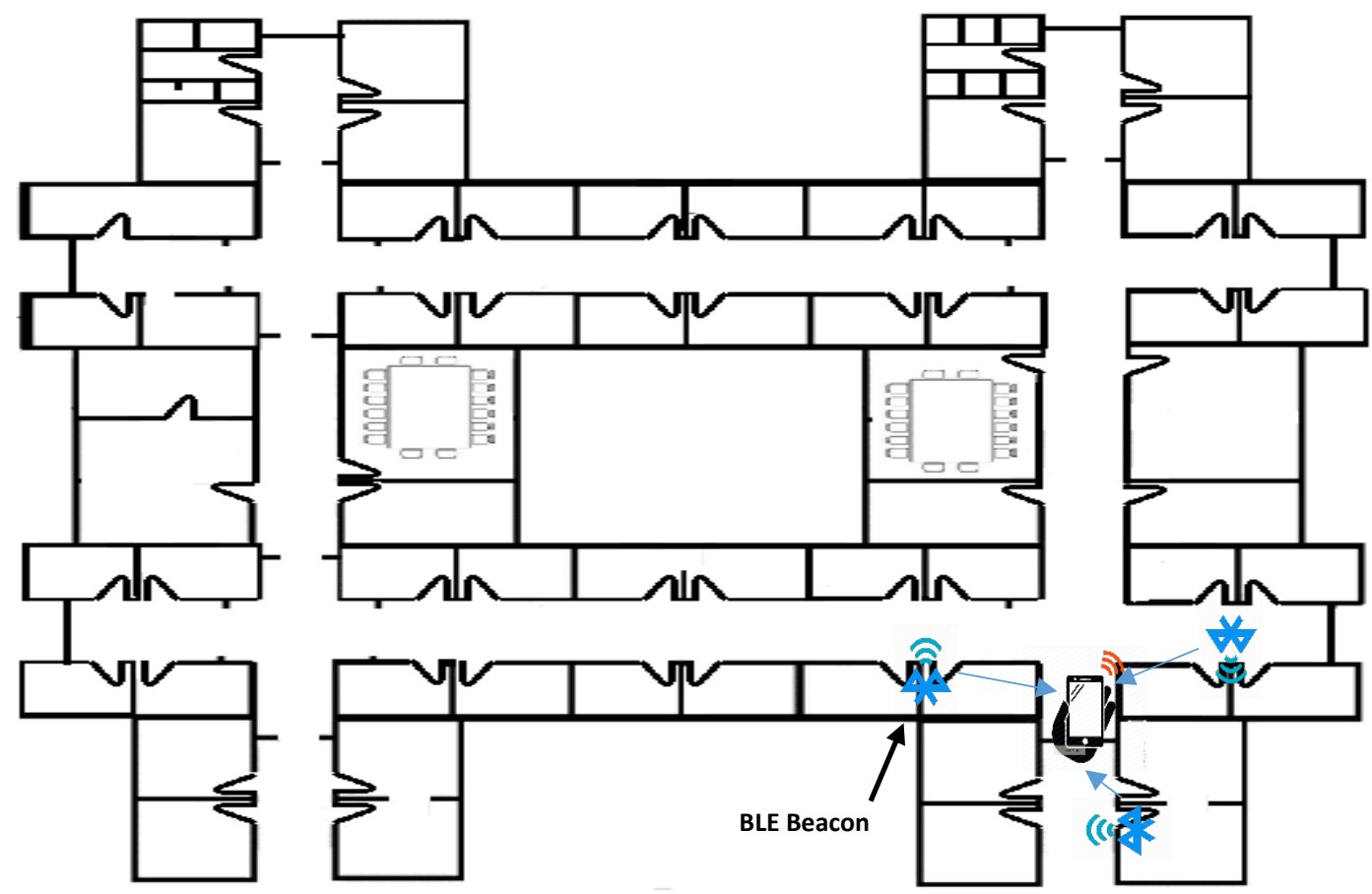

Figure 5: BLE beacons in 2D map at the department of Information Technology at QU
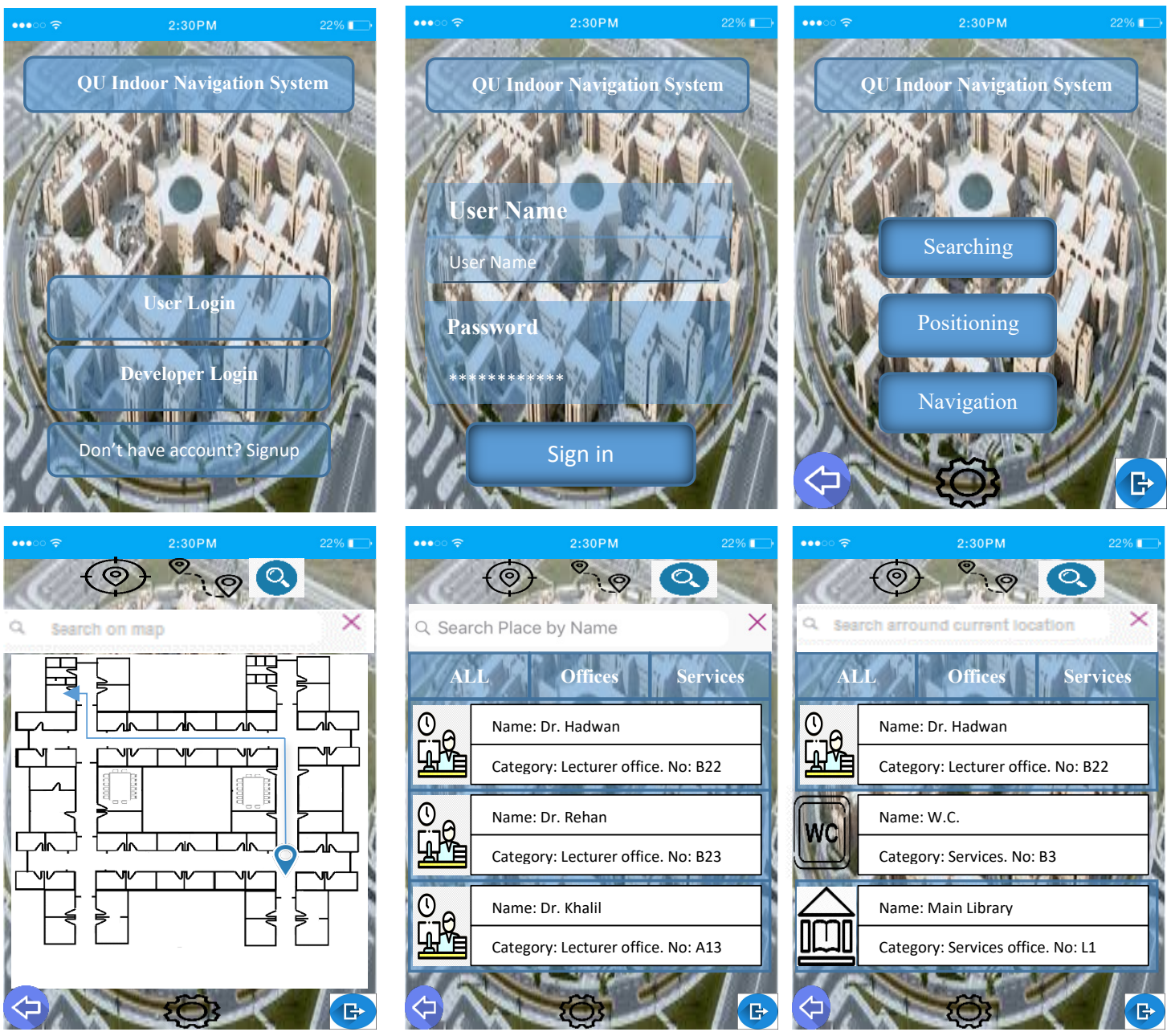

Figure 6: Screenshots of QU Indoor Navigation System 


\section{Conclusion}

The QU is considerably a large university having thousands of students and hundreds of functional units in the central building and spread across the different cities of the Al-Qassim province. Therefore, the QU can be considered as a small city where many elements need to be connected and decisions are made. The QU thus represents an optimal and practical scenario for the concept of a smart campus. As such, we addressed the INS at the QU in this work. We presented a literature review for smart campuses in general and smart universities in particular. In the INS, several technologies are explored for solving navigation and positioning in indoor areas. For an implementation and simulation perspective, the BLE beacon is selected because the BLE beacons are cheap, reliable, having a longer battery life. As such 454 user data is analyzed and is used to design a mobile application that includes all the services required by the users. The system architecture in addition to a 2D map helps in identifying the locations of BLE beacons to cover the whole area of the Information Technology Department at the College of Computer in QU. The system architecture is scalable in order to accommodate any building size. The work in this paper is conducted on the main campus of the QU; however, the extension to other setups involves minimum or similar infrastructure.

\section{Conflict of Interest}

The authors declare no conflict of interest.

\section{Acknowledgment}

The work in this article is funded in its entirety by the Deanship of Scientific Research (SRD), Project number: 5173-coc-2018-114-S at the Qassim University, Kingdom of Saudi Arabia.

\section{References:}

[1] R. Giffinger, C. Fertner, H. Kramar, R. Kalasek, N. Pichler-Milanovic, and E. Meijers, "Smart cities - Ranking of European medium-sized cities," Science, Centre of Regional, Smart Cities: Vienna, 2007.

[2] C. Yin, Z. Xiong, H. Chen, J. Wang, D. Cooper, and B. David, "A literature survey on smart cities," Science China Information Sciences, 58(10), 1-18, 2015.

[3] A. Abuarqoub, H. Abusaimeh, M. Hammoudeh, D. Uliyan, M. AbuHashem, M. Sharefa, M. Al-Jarrah, and F. Al-Fayez, "A Survey on Internet of Things Enabled Smart Campus Applications," in International Conference on Future Networks and Distributed Systems, Association for Computing Machinery: Cambridge, United Kingdom. 7, 2017.

[4] A. Alghamdi, and S. Shetty, "Survey Toward a Smart Campus Using the Internet of Things," in 2016 IEEE 4th International Conference on Future Internet of Things and Cloud (FiCloud), FiCloud: Vienna, 235-239, 2016.

[5] W. Villegas-Ch, X. Palacios-Pacheco, and S. Luján-Mora, "Application of a Smart City Model to a Traditional University Campus with a Big Data Architecture: A Sustainable Smart Campus," Sustainability, 11 , 2019.

[6] F. Zafari, A. Gkelias, and K. K. Leung, "A Survey of Indoor Localization Systems and Technologies," IEEE Communications Surveys \& Tutorials, 21(3), 2568-2599, 2019. DOI: 10.1109/COMST.2019.2911558

[7] R. Lea, and M. Blackstock, "Smart Cities: an IoT-centric Approach," in Proceedings of the 2014 International Workshop on Web Intelligence and Smart Sensing, Association for Computing Machinery: New York, NY, USA, 1-2, 2014.

[8] K. Al-Ani, W., Abdalkafor, A. S, and Nassar, A. M, "Smart City Applications: A Survey," in Proceedings of the 9th International www.astesj.com
Conference on Information Systems and Technologies, Association for Computing Machinery: Cairo, Egypt, 2019.

[9] R. M. Doheim, A. F. Alshimaa, and S. Badawi, "Smart city vision and practices across the Kingdom of Saudi Arabia - a review," Anna Visvizi and M.D. Lytras, Editors, Elsevier, 309-332, 2019. https://doi.org/10.1016/B978-0-12-816639-0.00017-X

[10] S. Alotaibi, and A. Alhussaini, "Smart campus project," in King Fahd University Of Petroleum And Minerals. 2014.

[11] O. Bates, and A .Friday, "Beyond data in the smart city: repurposing existing campus IoT,” IEEE Pervasive Comput, 16(2), 54-60, 2017. DOI: 10.1109/MPRV.2017.30

[12] S. Fortes; J. A. Santoyo-Ramón, D. Palacios, E. Baena, R. Mora-García, M. Medina, P. Mora, R. Barco, R. "The Campus as a Smart City: University of Málaga Environmental, Learning, and Research Approaches," Sensors, 19, 1349, 2019. https://doi.org/10.3390/s19061349

[13] T. Sutjarittham, T., H.H. Gharakheili, and S.S. Kanhere, "Realizing a smart university campus: vision, architecture, and implementation," in Proceeding of International Conference on Advanced Networks and Telecommunication Systems (ANTS), Indore, India, 2015.

[14] M. Cata, "Smart University, a new concept in the Internet of Things," in 14th RoEduNet International Conference, N.i.E.a. Research, Editor, Craiova, Romania, 2015.

[15] R. Faragher, and R. Harle, "Location fingerprinting with bluetooth low energy beacons," IEEE Journal on Selected Areas in Communications, 33(11), 2418-2428, 2015. DOI: 10.1109/JSAC.2015.2430281

[16] M. Kadadha, H. Al-Ali, M. A. Mufti, A. Al-Aamri, and R. Mizouni, "Opportunistic mobile social networks: Challenges survey and application in smart campus," IEEE 12th International Conference on Wireless and Mobile Computing, in Networking and Communications (WiMob), New York, USA, 1-8, 2016.

[17] A. Kamilaris, A., D. T. H. Ngan, A. Pantazaras, B. Kalluri, S. Kondepudi, and T. K. Wai, "Good practices in the use of ICT equipment for electricity savings at a university campus," in International Green Computing Conference, Dallas, TX, USA, 1-11, 2014.

[18] K. Bandara, P. Jayalath, A.U. Rodrigo, Z. Bandaranayake, Z. Maraikar, and R. G. Ragel, "Smart campus phase one: Smart parking sensor network," in Manufacturing \& Industrial Engineering Symposium (MIES), Colombo, 16, 2016.

[19] A. Petcovici, and E. Stroulia, "Location-based services on a smart campus: A system and a study," in IEEE 3rd World Forum on Internet of Things (WF-IoT), Reston, VA. 94-99, 2016.

[20] K. A. Nuaimi, and H. Kamel, "A survey of indoor positioning systems and algorithms," in international conference on Innovations in information technology (IIT), IEEE, 185-190, 2011.

[21] A. Puikkonen, A. Sarjanoja, M. Haveri, J. Huhtala and H. Jonna, "Towards designing better maps for indoor navigation: experiences from a case study," in Proceedings of the 8th International Conference on Mobile and Ubiquitous Multimedia (MUM '09), A.f.C. Machinery, Editor, New York, NY, USA, 1-4, 2009.

[22] O. A. Hammadi, A. A. Hebsi, M. J. Zemerly, and J. W. P. Ng, "Indoor Localization and Guidance Using Portable Smartphones," in IEEE/WIC/ACM International Conferences on Web Intelligence and Intelligent Agent Technology. IEEE: Macau, 337-341, 2012.

[23] J. Torres-Sospedra, J. Avariento, D. Rambla, R. Montoliu, Sven Casteleyn, Mauri Benedito-Bordonau, Michael Gould, and J. Huerta, "Enhancing integrated indoor/outdoor mobility in a smart campus," Int. J. Geogr. Inf. Sci. 29,2015

[24] A. Möller, K., Matthias, H. Robert, D. Stefan and R. Luis. A Mobile Indoor Navigation System Interface Adapted to Vision-Based Localization," In Proceedings of the 11th International Conference on Mobile and Ubiquitous Multimedia. 2012. Ulm, Germany: Association for Computing Machinery.

[25] L. Zhu, A. Yang, D. Wu, and L. Liu, "Survey of Indoor Positioning Technologies and Systems, in Life System Modeling and Simulation," L.S.M.a. Simulation, Editor. Springer: Berlin, Heidelberg, 2014.

[26] L. Mainetti, L. Patrono, and I. Sergi, "A survey on indoor positioning systems," in 22nd International Conference on Software, Telecommunications and Computer Networks, SoftCOM, Editor. Split, Croatia. 111-120, 2014.

[27] W. Sakpere, M. A. Oshin, and N. B. Mlitwa, "A State-of-the-Art Survey of Indoor Positioning and Navigation Systems and Technologies," South African Computer Journal (SACJ) 29(3), 145-197, 2017. http://dx.doi.org/10.18489/sacj.v29i3.452 
[28] J. Candy, A Mobile Indoor Location-Based GIS Application, in International Symposium on Mobile Mapping Technologie ," Padua, Italy, 2007.

[29] M. Kotaru, K. Joshi, D. Bharadia and S. Katti, Spotfi: "Decimeter level localization using WiFi," ACM SIGCOMM Computer Communication Review, 45, 269-282 2015.

[30] C. Tsirmpas, A. Rompas, O. Fokou, and D. Koutsouris, "An indoor navigation system for visually impaired and elderly people based on Radio Frequency Identification (RFID) ," Information Sciences, 320, 288-305, 2015.

[31] E. M. Gorostiza, J. L. L. Galilea, F. J. M. Meca, D. S. Monzú, F. E. Zapata and L. P. Puerto, "Infrared sensor system for mobile-robot positioning in intelligent spaces,” Sensors, 11(5), 5416-5438, 2011. https://doi.org/10.3390/s110505416

[32] S. Gezici, "Localization via ultra-wideband radios: a look at positioning aspects for future sensor networks," IEEE Signal Processing Magazine, 22, $70-84,2005$

[33] M.Sreeja and M. Sreeram, "Bluetooth 5 beacons: a novel design for indoor positioning," in Proceedings of the Second International Conference on Internet of things, Data and Cloud Computing, Association for Computing Machinery: Cambridge, United Kingdom, 2017.

[34] P. Kriz, F. Maly, and T. Kozel, "Improving Indoor Localization Using Bluetooth Low Energy Beacons," Mobile Information Systems, 2083094, 2016.

[35] X. Zhao, Z. Xiao, A. Markham, N. Trigoni, and Y. Ren, "Does BTLE measure up against WiFi? A comparison of indoor location performance," in European Wireless, 20th European Wireless Conference. 2014.

[36] Z. Zuo, L. Liu, L. Zhang, and Y. Fang, Indoor Positioning Based on Bluetooth Low-Energy Beacons Adopting Graph Optimization. Sensors 2018.

[37] B. Jan, O. Klapka, T. Kozel, and M. Zmitko, "Method of iBeacon Optimal Distribution for Indoor Localization," Cham: Springer International Publishing, 2015 